\title{
The role of social support in posttraumatic growth in people struggling with cancer
}

The experience of cancer, in addition to a number of ad-
verse effects that manifest themselves in different spheres
of functioning, may also serve human development. This
was confirmed by recent studies on posttraumatic growth.
This phenomenon requires the presence of positive chang-
es in self-perception, interpersonal relationships, and phi-
losophy of life, which appear as a result of attempts to
cope with the aftermath of traumatic events.
Studies indicate that the incidence of positive changes as
a result of the experience of cancer is quite high and occurs
in $30-90 \%$ of patients. They relate mainly to the relation-

\begin{abstract}
ships with other people and an appreciation of life and are characteristic especially for the early stages of diagnosis and treatment of cancer. Among the factors determining posttraumatic growth, a key role is attributed to social support. This paper presents the role of social support in the process of developing positive changes after the trauma associated with the experience of cancer, including the types and sources of support.
\end{abstract}

KEY WORDS

posttraumatic growth; cancer; social support

ORganizations - Institute of Psychology, University of Lodz, Poland

AUthors' CONTRIBUtion - A: Study design - B: Data collection - C: Statistical analysis - D: Data interpretation .

E: Manuscript preparation · F: Literature search · G: Funds collection

Corresponding AUthor - Prof. Nina Ogińska-Bulik, Institute of Psychology, University of Lodz, 10/12 Smugowa Str.,

91-433 Lodz, Poland, tel. +48 4266555 12, e-mail: noginska@uni.lodz.pl

TO CITE THIS ARTICLE - Ogińska-Bulik, N. (2013). The role of social support in posttraumatic growth in people struggling

with cancer. Health Psychology Report, 1, 1-8. DOI: 10.5114/hpr.2013.40464 
Disease is an integral part of human life. Its conscious experiencing gives life value, greater than that offered by health alone.

\section{CANCER DISEASE AS A TRAUMATIC EXPERIENCE}

The experience of cancer disease has many negative after-effects, which manifest in various spheres of human functioning, mostly in the emotional sphere. Coping with neoplasm is accompanied by feelings of danger, anxiety, depression, helplessness, uncertainty, concerns for the future, and sometimes also feelings of guilt or changes in self-image. The experience of the disease is also associated with limitations in one's activity, inability or difficulty in achieving life objectives in both the familial and occupational sphere. Also, a person may develop changes in cognitive functioning. According to Heszen-Niejodek (2003), disease poses a threat to principle values of a human being, i.e. self-assessment, physical fitness, social relationships, and, most of all, one's life.

According to Lazarus' theory of stress, the situation of disease should be considered as harm/loss and threat. In view of Hobfoll's conservation of resources model, disease should be interpreted as loss of significant resources. As a result of the disease, one loses not only health, but also other resources, e.g. material, familial, occupational, or personal (for example self-dignity).

Undoubtedly, the experience of chronic somatic disease, especially cancer disease, constitutes a strong stressor for patients and their families. Particularly strong stress is associated with the therapeutic process, e.g. the necessity of undergoing surgery or chemotherapy.

Trauma associated with the experience of chronic somatic disease usually has a complex character. This results from the multitude of negative experiences of an individual. Consequently, one can identify trauma associated with the diagnostic process, the severity of the disease, and the resultant mortality risk, feelings of loneliness (e.g. during hospitalization), duration of the disease, repeated medical procedures, or the general awareness of being sick (Devine et al., 2010).

The experiencing of cancer disease can cause symptoms characteristic for posttraumatic stress disorder (PTSD). This was confirmed, inter alia, by Butler et al. (1999), who observed that female oncological patients show higher levels of intrusion and avoidance than individuals who experienced other negative life events. Another study of breast cancer patients (Cordova $e t$ al., 2000) revealed posttraumatic stress disorder in $8.5 \%$ of the studied women. The prevalence of PTSD symptoms in cancer patients was also documented in a Polish study (Widera, Juczyński \& Popiela, 2003). Women with breast cancer displayed levels of three main PTSD-specific factors: intrusion, avoidance, and hyperarousal (measured with the Impact of Event Scale, IES-R), similar to those of individuals who experienced such events as rape or imprisonment.

Consequently, searching for factors that would enable one to cope with trauma and adjust to a disease becomes of vital importance. The list of these factors includes, inter alia, the way of coping. Efficient coping with such traumatic experience as cancer disease can be reflected by positive changes in psychological functioning, referred to as posttraumatic growth.

\section{THE PHENOMENON OF POSTTRAUMATIC GROWTH}

The term posttraumatic growth (PTG) was introduced by R. Tedeschi and L. Calhoun (1996). It refers to positive changes that develop as a result of attempts to cope with the consequences of traumatic events. Therefore, posttraumatic growth is more than just recovery after an experienced traumatic event. An individual experiencing posttraumatic growth undergoes some kind of transformation in response to trauma, and reaches levels of functioning higher than prior to trauma.

Tedeschi and Calhoun (1996, 2004) ${ }^{1}$ identified three types of positive changes that take place during posttraumatic growth. The changes refer to self-perception, interpersonal relationships, and life philosophy. After traumatic events, some people feel stronger and more mature, aware of their greater capacity of coping and surviving in extreme situations; they are aware of new possibilities in life, and set themselves new objectives. Efficient coping with traumatic events can be reflected by higher self-value and self-efficacy, as well as greater trust in oneself and one's abilities, including with regards to future events.

Many persons who have experienced trauma show greater sensibility and sympathy to others, and learn on whom they can rely in a crisis. Moreover, such individuals are more prone to opening to others, and feel better in such relationships. In response to traumatic experience they have found the power which enables them to put their previous life into perspective and improve it.

Individuals who show posttraumatic growth in response to experienced traumatic situations pay more attention to small everyday situations, and seem to minimize important life issues. Family, friends, and small everyday pleasures can be perceived as more important than issues that were previously ranked first (e.g. professional career). The experience of trauma can also lead to changes in existential (religious) beliefs of an individual. People who faced critical situations show greater appreciation of life and experience it more consciously (Tedeschi \& Calhoun, 2007). 
The existence of posttraumatic growth does not necessarily mean that experiencing trauma should be considered a positive event or a prerequisite of significant changes in one's life. Furthermore, it should not be equated with the feeling of happiness. Nevertheless, posttraumatic growth represents a chance for a more meaningful and more valuable life. However, one should not expect that posttraumatic growth will develop in every person who has experienced trauma, or that it constitutes a prerequisite for full recovery after trauma. It is not trauma itself, but rather the actions undertaken by an individual in order to cope with a crisis, which lead to posttraumatic growth (Tedeschi \& Calhoun, 2007).

\section{POSTTRAUMATIC GROWTH IN CANCER DISEASE}

Studies of adults determined that the experience of cancer disease can be associated with the presence of posttraumatic growth. The percentage of patients who experience positive changes after being diagnosed with cancer is estimated at $30-90 \%$ (Tedeschi, Park \& Calhoun, 1998; Mystakidou et al., 2008). The presence of posttraumatic growth is characteristic mainly for early stages of the process of diagnosing and treating cancer. Positive changes refer mostly to relationships with other people and appreciation of life. This phenomenon was observed in individuals with various malignancies (Mystakidou et al., 2008). Similar changes, manifested by strengthening bonds with others, appreciation of life, and spiritual changes, were observed among women with breast cancer (Cordova, Cunnigham, Carlson \& Andrykowski, 2001; Zemore \& Shepel, 1989). A Polish study conducted in a group of mastectomized women (Ogińska-Bulik, 2010), among them $50 \%$ showing high levels of posttraumatic growth, documented that the most pronounced changes pertained to relationships with other people and appreciation of life, rather than to self-perception and the spiritual sphere.

The development of positive changes after trauma associated with the experience of cancer disease was also documented among children and adolescents (Phipps, Long \& Ogden, 2007; Michel, Taylor, Absolom \& Eiser, 2010; Devine et al., 2010). Barakat et al. (2006) claimed that nearly $85 \%$ of surveyed teenagers noted at least one positive change resulting from the experienced disease, and nearly $1 / 3$ declared the presence of at least four changes. In more than half of the respondents, these positive changes were associated with self-perception and future plans. Development of positive changes in response to trauma associated with the experience of cancer disease was also documented among Polish teenagers (Ogińska-Bulik, 2012). $36 \%$ of the respondents experienced high levels of posttraumatic growth (compared with $33 \%$ and $31 \%$ of individuals experiencing low or moderate levels of growth, respectively). Contrary to adult female oncological patients (Ogińska-Bulik, 2010), the positive changes referred to self-perception and appreciation of life, rather than to relationships with other people.

Irrespective of the type of experienced trauma, posttraumatic growth is an outcome of multiple factors, including the intensity of the experienced event, the magnitude of health and life risk, time elapsed from exposure to this risk, ways of coping with the life experience, and individual characteristics (Ogińska-Bulik, 2013). Social support is also a determinant of posttraumatic growth.

\section{THE ROLE OF SOCIAL SUPPORT IN THE PROCESS OF POSTTRAUMATIC GROWTH}

Social support is usually defined as a resource provided by other people in order to help individuals in difficult situations (Sęk \& Cieślak, 2004). Social support plays an important role in coping with chronic somatic disease. It enables the expression of negative emotions, enhances the feelings of closeness, preserves relationships, improves psychological wellbeing, and promotes the choice of more efficient coping strategies. The role of social support is mainly helping the afflicted persons to mobilize all resources in order to cope with their condition more efficiently.

The results of available research suggest that social support also increases the probability of developing positive changes after trauma. This refers to both the availability of support and perceived or obtained support. Emotional support represents a particularly important type of help, especially if obtained immediately after an experienced traumatic event. The possibility of sharing thoughts and feelings, and expressing emotions, supports the processing of trauma and raises the chances for posttraumatic growth (Tedeschi \& Calhoun, 1996, 2007). Harvey et al. (2004) emphasized that the possibility of sharing emotions with other people is a key factor in the process of coping with trauma. Therefore, the availability of a support network, including formal groups offering help to individuals in need, is of vital importance. This type of support promotes positive changes even in those traumatized persons who do not seek help actively.

Tedeschi and Calhoun (2004) suggested that the important role of support is associated with the fact that offered support mobilizes persons experiencing trauma to active, problem-oriented rumination (deliberate rumination). In contrast to intrusive rumination, this type of rumination has defined objectives and leads to adaptive reinterpretation of cognitive schemes regarding the world and the self, and establishing a new, more realistic vision of reality, which in turn promotes the development of positive chang-
Social support in posttraumatic growth 
es. Support from persons who have experienced or still experience similar trauma is vitally important, albeit difficult. Self-comparison with persons who are in even more difficult situations and still cope with trauma can constitute a very important and supportive source of power. This was emphasized by Taylor (1983) in her concept of cognitive adaptation.

Perceived social support, i.e. the awareness of having persons who could offer support in a crisis, seems a more important determinant of efficient coping with trauma and resultant positive changes than the availability of the support itself. Being convinced of having support promotes choosing more efficient coping strategies. Seeking support, both instrumental and emotional, is associated mostly with realizing new possibilities in life and improving relationships with others.

Perceived social support proved to be a predictor of posttraumatic growth (both in the case of the global score and its three dimensions) of patients with rheumatoid arthritis (Dirik \& Karanci, 2008). A positive, albeit weak, correlation between support and posttraumatic growth was also documented in individuals mourning the loss of a close relative who died of HIV/AIDS (Cadell, Regehr \& Hemsworth, 2003).

Social support also promotes posttraumatic growth in cancer patients. This was, inter alia, confirmed in the case of women with breast cancer (Bussel \& Naus, 2010; Lechner \& Antoni, 2004; Lelorain, Tessier, Florin \& Bonnaud-Antignac, 2012; Weiss, 2004), men with prostate cancer (Thornton \& Perez, 2006), and individuals after bone marrow transplantation (Tallman, Shaw, Schultz \& Altmaier, 2010), as well as in patients with other malignancies (Nenova et al., 2013; Schroevers, Helgeson, Sanderman \& Ranchor, 2010; Tanriverd, Savas \& Can, 2012; Texteira \& Pereira, 2013).

However, the role of support in the process of developing positive posttraumatic changes seems complex, and its effect is determined by many factors, including the type of support and its sources. Based on the available data, one cannot unambiguously identify the types of support that play a more important role during posttraumatic growth in cancer patients. Mainly the role of emotional and instrumental support is emphasized in the literature. Studies of women with breast cancer revealed that mostly emotional support promotes posttraumatic growth (Manne et al., 2004). However, one recently published study dealing with the discussed problem (Nenova et al., 2013) documented a positive association between both types of support obtained from spouses/partners; nevertheless, it was instrumental support that turned out to be the stronger predictor of posttraumatic growth.

Questions arise as to which, perceived or obtained support, is more important for posttraumatic growth after experiencing cancer disease, and what is the role of satisfaction with obtained support. One can try to answer these questions based on the results of longitudinal studies, analyzing three aspects of emotional support: subjectively perceived availability of support, obtained support, and satisfaction with obtained support. These parameters were examined twice, three months after diagnosing cancer and eight years thereafter. Analysis of regression identified support obtained three months after diagnosing the disease as the main predictor of posttraumatic growth (determined eight years after the diagnosis) (Schroevers et al., 2012).

The results of the abovementioned studies raise questions on the role of timing of social support in the process of adjustment to a disease and the development of positive posttraumatic changes. Namely, one should ask whether support offered immediately after establishing the diagnosis is more efficient than that proposed later, in the course of the therapeutic process or even after its completion. The results of available studies do not provide equivocal answers to this question.

A study of women with breast cancer showed that a lower demand for social support promoted posttraumatic growth at the stage of diagnosis and during the initial period of treatment. However, it was greater demand for social support which correlated positively with posttraumatic growth six months after the surgical treatment. Finally, social support did not influence the level of posttraumatic changes one year after the surgical treatment (Lechner \& Antoni, 2004).

Similar results were documented in another study analyzing coping strategies of women with breast cancer (Bussel \& Naus, 2010). While religious coping proved the only predictor of posttraumatic growth during treatment (chemotherapy), positive reinterpretation and seeking support, both instrumental and emotional, also played an important role in the development of positive posttraumatic changes during later stages of recovery. However, the results of the previously mentioned study by Schroevers et al. (2010) suggested that support offered earlier, i.e. three months after diagnosing the disease, promotes positive posttraumatic changes. This suggests that the process of coping with cancer disease is dynamic, and the level of posttraumatic growth is associated with demand for support, which is specific for the given clinical stage of the disease and phase of its treatment.

Linley and Joseph (2004) emphasized that it is not the support itself, but rather satisfaction with obtained social support which is important for people who have experienced trauma. This would, at least partially, explain the results of the studies which did not confirm the role of social support in posttraumatic growth after trauma associated with the experience of cancer disease (Cordova, Cunnigham, Carlson \& Andrykowski, 2001; Schmidt, Blank, Bellizzi \& Park, 2012; Sears, Stanton \& Danoff-Burg, 2003; Widows, Jacobsen, Booth-Jones \& Fields, 2005). 
The case is similar with other traumatic experiences. Studies of the posttraumatic growth of cardiac patients (Sheik, 2004), and HIV-infected persons in the United States, who experienced trauma due to hurricane Katrina (Cieslak et al., 2009) did not confirm the role of support in the growth process. In this latter study, the support turned out to be positively correlated with only one factor included in the Posttraumatic Growth Inventory, namely, relationships with other people. The authors explained this lack of significant associations by the fact that the role of support was analyzed solely with regards to the two months prior to the study. Perhaps social support played a significant role only in the case of delayed effects of posttraumatic growth. Moreover, social support turned out to be weakly correlated with posttraumatic growth of Polish teenagers who were victims of road accidents. Instrumental support from relatives was the only one of the eight sources and four types of support analyzed, which correlated positively with the overall score of the Personal Development Questionnaire. Moreover, it was correlated with changes in relationships with others. Additionally, there was a correlation between information support from school teachers and changes in self-perception (Ogińska-Bulik \& Kwarta, 2012).

On the other hand, the results of a study of women with breast cancer from Slovenia (Svetina \& Nastran, 2012) suggest that satisfaction with family reduces the levels of posttraumatic growth. Presumably, satisfaction with family was associated with lesser predisposition of an individual to be involved in the process of posttraumatic changes, which affected posttraumatic growth negatively.

During coping with a disease, a particular role is ascribed to support from close relatives, mostly family members. This was confirmed by the results of a Turkish study of patients with various malignancies. The study analyzed support from three sources: family, friends, and other important persons. Posttraumatic growth was promoted by the first two sources of support; however, support from family members proved to be the strongest reinforcement (Tanriverd et al., 2012).

The role of support from close relatives in benefiting from a disease was also documented in an Israeli study of female breast cancer survivors (Weiss, 2004). Women who obtained greater support from their husbands benefited more than those who received less help. Moreover, the participants staying in touch with other women, who successfully coped with and benefited from their disease, were documented to display greater amounts of positive posttraumatic changes. This would point to a significant role of posttraumatic growth modeling.

However, the results of some available studies do not confirm the role of support from close relatives. A study of children with cancer disease (Yaskowich,
2003) showed that, while the support obtained from school teachers promoted posttraumatic growth, the support from parents and peers did not influence the development of positive posttraumatic changes.

Furthermore, researchers tried to explain whether social support offered to cancer patients stimulates posttraumatic growth in a global context, or rather solely in particular domains. This issue was partially explained by the results published by Luszczynska et al. (2005), who examined a group of patients subjected to surgical resection of a neoplasm. The posttraumatic growth was analyzed with the Benefit Finding Scale. Receiving social support promoted only two out of four analyzed areas of noted benefits, i.e. changes in family relations and greater sensitivity to others.

Wortman (2004) pointed to a complex role of support in the process of posttraumatic growth, also emphasizing negative aspects of help. Moreover, the author suggested that these negative consequences can have a greater impact on the mental health of individuals experiencing a crisis. In many cases, the offered support can be assessed as inefficient due to various reasons. One of them is the lack of competences in offering support. Some people feel helpless seeing the suffering of a person, and do not know how to respond. As a result, many of them keep distance from persons in crisis, or avoid them.

Staying with a person who has experienced trauma can make one more prone to negative feelings. This, in turn, may stimulate not only the lack of sympathy for a patient, but also anger, fatigue, or even hostility. Some people may believe that individuals who have experienced a negative life event deserved their suffering. As a result, they are convinced that the world is just, and that they will never experience a similar situation themselves. Such persons try to discourage individuals in crisis from talking about their trauma or expressing emotions associated therewith. Moreover, they frequently minimize the feelings of an afflicted person, or even try to impose their own, positive, vision of the world. Suggestions, such as "it is time to begin a new life" or "it is time for you to act" may cause negative responses from persons affected by trauma. This makes the knowledge on "whom, when, and how to offer support" vitally important.

One should remember about the phenomenon documented by Harvey et al. (2004), who observed that negative reactions of people from whom a traumatized individual sought help can play a significant stimulatory role in the development of positive posttraumatic changes. Certain reactions, such as disbelief, avoidance, or even hostility, can be more effective than consolation or saying "I know how you feel" or "all will be well". Paradoxically, reactions of this type can stimulate a traumatized person to reprocess a crisis event and make further attempts to cope with it. Comprehensive analysis of types of support required by a given person becomes crucial in this context.
Social support in posttraumatic growth 
The complex role of social support in posttraumatic growth is also associated with the relation between social support and other determinants of positive posttraumatic changes. Personal characteristics of an individual and the types of their coping strategies constitute the most important factors from the latter group. Among personal characteristics, gender seems particularly important for the development of posttraumatic growth, as women have been proven to benefit more from traumatic experiences. More-
Nina Ogińska-Bulik over, gender is associated with being able to benefit from social support, as women have been shown to be more prone to seek help. Also other personal characteristics, mostly related to personality, can determine posttraumatic growth on the one hand, and influence perception and utilization of social support on the other. For example, extravert persons are more likely to make use of help from others in negative life situations than introverts, who more often show a tendency to "rely on themselves".

Individual characteristics also determine the choice of trauma coping strategies. Therefore, social support seems to be an intervening variable between personal characteristics of an individual, strategies used to cope with trauma, and consequences of the latter.

\section{CONCLUSIONS}

Social support undoubtedly plays a positive role in the development of desirable changes after trauma associated with cancer disease. Particular emphasis should be put on emotional and instrumental support. Both obtained and self-perceived support are equally important for the process of posttraumatic growth. Support from close relatives is the main determinant of benefiting from a disease. Also negative support can play an important role in the development of posttraumatic growth-related changes in some patients. In order to provide efficient social support, one should consider individual characteristics of persons in need and adjust the offered support to their expectations.

In conclusion, the availability of support and predisposition of an individual to perceive and utilize various forms of help offered by other people promote the development of positive changes associated with posttraumatic growth. On the other hand, a deficit of support will likely lead to persistence of pathological signs.

\section{ENDNOTES}

1 Positive posttraumatic changes have been widely discussed by N. Ogińska-Bulik, in her book "The Positive Aspects of Traumatic Experiences, or When Tears Turn Into Pearls”.

\section{RefERENCES}

Barakat, L., Alderfer, M. \& Kazak, A. (2006). Posttraumatic growth in adolescent survivors of cancer and their mothers and fathers. J Pediatr Psychol, 31, 413-419.

Bussel, V. \& Naus, M. (2010). A longitudinal investigation of coping and posttraumatic growth in breast cancer survivors. J Psychosoc Oncol, 28, 61-78.

Butler, L.D., Koopman, C., Classen, C. \& Spiegel, D. (1999). Traumatic stress, life events, and emotional support in women with metastatic breast cancer: cancer-related traumatic stress symptoms associated with past and current stressors. Health Psychol, 18, 555-560.

Cadell, S., Regehr, C. \& Hemsworth, D. (2003). Factors contributing to posttraumatic growth: a proposed structure equation model. Am J Orthopsychiatry, 73, 279-287.

Cieslak, R., Benight, C., Schmidt, N., Luszczynska, A, Curtin, E., Clark, R. \& Kissinger, P. (2009). Predicting posttraumatic growth among Hurricane Katrina survivors living with HIV: the role of self-efficacy, social support, and PTSD symptoms. Anxiety Stress Coping, 22, 449-463.

Cordova, M.J., Cunnigham, L.L.C., Carlson, C.R. \& Andrykowski, M.A. (2001). Posttraumatic growth following breast cancer: a controlled comparison study. Health Psychol, 20, 176-185.

Cordova, M.J., Studs, J.L., Hann, D.M., Jacobsen, P.B. \& Andrykowski, M.A. (2000). Symptom structure of PTSD following breast cancer. J Trauma Stress, 13, 301-309.

Devine, K., Reed-Knight, B., Loiselle, K., Fenton, N. \& Blount, R. (2010). Posttraumatic growth in young adults who experienced serious childhood illness: a mixed-methods approach. J Clin Psychol Med Settings, 17, 340-348.

Dirik, G. \& Karanci, A.N. (2008). Variables related to posttraumatic growth in Turkish rheumatoid arthritis patients. J Clin Psychol Med Settings, 15, 193-203.

Harvey, J., Barnett, K. \& Overstreet, A. (2004). Trauma growth and other outcomes attendant to loss. Psychological Inquiry, 15, 26-29.

Heszen-Niejodek, I. (2003). Psychologiczne problemy chorych somatycznie. In: Strelau J. (ed.). Psychologia. Podręcznik akademicki [Psychology. Academic textbook] (pp. 513-524). Gdańsk: GWP.

Lechner, S.C. \& Antoni, M.H. (2004). Posttraumatic growth and group-based intervention for persons dealing with cancer: What have we learned so far? Psychological Inquiry, 15, 35-41.

Lelorain, S., Tessier, P., Florin, A. \& Bonnaud-Antignac, A. (2012). Posttraumatic growth in long term breast cancer survivors: relation to coping, social support and cognitive processing. J Health Psychol, 17, 627-639. 
Linley, P.A. \& Joseph, S. (2004). Positive change following trauma and adversity: A review. J Trauma Stress, 17, 11-21.

Luszczynska, A., Mohamed, N. \& Schwarzer, R. (2005). Self-efficacy and social support predict benefit finding 12 months after cancer surgery: The mediating role of coping strategies. Psychology, Health \& Medicine, 10, 365-375.

Manne, S., Ostroff, J., Winkel, G., Goldstein, L., Fox, K. \& Grana, G. (2004). Posttraumatic growth after breast cancer: patient, partner, and couple perspectives. Psychosom Med, 66, 442-454.

Michel, G., Taylor, N., Absolom, K. \& Eiser, C. (2010). Benefit finding in survivors of childhood cancer and their parents: further empirical support for the Benefit Finding Scale for Children. Child Care, Health Dev, 36, 123-129.

Mystakidou, K., Tsilika, E., Parpa, E., Galanos, A. \& Vlahos, L. (2008). Post-traumatic growth in advanced cancer patients receiving palliative care. $\mathrm{Br}$ J Health Psychol, 13, 633-646.

Nenova, M., DuHamel, K., Zenon, V., Rini, C. \& Redd, W.H. (2013). Posttraumatic growth, social support, and social constraint in hematopoietic stem cell transplant survivors. Psychooncology, 22, 195-202.

Ogińska-Bulik, N. (2010). Potraumatyczny rozwój w chorobie nowotworowej - rola prężności. Pol Forum Psych, 15, 125-139.

Ogińska-Bulik, N. (2012). Osobowy wzrost u nastolatków zmagających się z chorobą nowotworową. Psychoonkologia, 1, 1-8.

Ogińska-Bulik, N. (2013). Pozytywne skutki doświadczeń traumatycznych, czyli kiedy łzy zamieniają się w perty [The Positive Aspects of Traumatic Experiences, or When Tears Turn Into Pearls]. Warszawa: Wyd. Difin.

Ogińska-Bulik, N. \& Kwarta, P. (2012). Potraumatyczny wzrost u dzieci i młodzieży - ofiar wypadków drogowych - rola wsparcia społecznego. Pediatria Polska, 87, 552-559.

Phipps, S., Long, A. \& Ogden, J. (2007). Benefit finding scale for children: Preliminary findings from a childhood cancer population. J Pediatr Psychol, 32, 1264-1271.

Schmidt, S., Blank, T., Bellizzi, K. \& Park, C. (2012). The relationship of coping strategies, social support, and attachment style with posttraumatic growth in cancer survivors. J Health Psychol, 17, 1033-1040.

Schroevers, M.J., Helgeson, V.S., Sanderman, R. \& Ranchor, A.V. (2010). Type of social support matters for prediction of posttraumatic growth among cancer patients. Psychooncology, 19, 46-53.

Sears, S.R., Stanton, A.L. \& Danoff-Burg, S. (2003). The yellow brick road and the emerald city: benefit finding, positive reappraisal coping, and posttraumatic growth in women with early-stage breast cancer. Health Psychology, 22, 487-496.
Sęk, H. \& Cieślak, R. (2004). Wsparcie społeczne - sposoby definiowania, rodzaje i źródła wsparcia, wybrane koncepcje teoretyczne. In: H. Sęk, R. Cieślak (eds.). Wsparcie spoteczne, stres i zdrowie [Social support, stress and health] (pp. 11-28). Warszawa: PWN.

Sheik, A.I. (2004). Posttraumatic growth in the context of heart disease. J Clin Psychol Med Settings, 11, 265-273.

Svetina, M. \& Nastran, K. (2012). Family relationships and posttraumatic growth in breast cancer patients. Psychiatria Danubina, 24, 298-306.

Tallman, B., Shaw, K., Schultz, J. \& Altmaier, E. (2010). Well-being and posttraumatic growth in unrelated donor marrow transplant survivors: a nine-year longitudinal study. Rehabil Psychol, 55, 204-210.

Tanriverd, D., Savas, E. \& Can, G. (2012). Posttraumatic growth and social support in Turkish patients with cancer. Asian Pac J Cancer Prev, 13, 4311-4314.

Taylor, S.E. (1983). Adjustment to threatening events: A theory of cognitive adaptation. Am Psychol, 38, 1161-1173.

Tedeschi, R.G. \& Calhoun, L.G. (1996). The Post-Traumatic Growth Inventory: measuring the positive legacy of trauma. J Trauma Stress, 9, 455-471.

Tedeschi, R.G. \& Calhoun, L.G. (2004). Posttraumatic growth: conceptual foundations and empirical evidence. Psychological Inquiry, 15, 1-8.

Tedeschi, R.G. \& Calhoun, L.G. (2007). Podejście kliniczne do wzrostu po doświadczeniach traumatycznych. In: P.A. Linley, S. Joseph (eds.). Psychologia pozytywna w praktyce [Positive psychology in practice] (pp. 230-248). Warszawa: PWN.

Tedeschi, R.G., Park, C.L. \& Calhoun, L.G. (1998). Posttraumatic growth: Conceptual issues. In: R.G. Tedeschi, C.L. Park, L.G. Calhoun (eds.). Posttraumatic growth: Positive changes in the aftermath of crisis (pp. 1-22). Mahwah: Erlbaum.

Texteira, R. \& Pereira, M. (2013). Factors contributing to posttraumatic growth and its buffering effect in adult children of cancer patients undergoing treatment. J Psychosoc Oncol, 31, 235-265.

Thornton, A.A. \& Perez, M.A. (2006). Postraumatic growth in prostate cancer survivors and their partners. Psychooncology, 15, 285-296.

Weiss, T. (2004). Correlates of posttraumatic growth in married breast cancer survivors. J Social Clin Psychol, 23, 733-746.

Widera, A., Juczyński, Z. \& Popiela, T. (2003). Psychologiczne wyznaczniki stresu pourazowego u pacjentów onkologicznych po okaleczających zabiegach chirurgicznych. Psychoonkologia, 7, 31-36.

Widows, M.R., Jacobsen, P.B., Booth-Jones, M. \& Fields, K.K. (2005). Predictors of posttraumatic growth following bone marrow transplantation for cancer. Health Psychol, 24, 266-273.
Social support in posttraumatic growth 
Wortman, C.B. (2004). Posttraumatic growth: progress and problems. Psychological Inquiry, 15, 81-90.

Yaskowich, K.M. (2003). Posttraumatic growth in children and adolescents with cancer. Dissertation Abstract International. The Sciences and Engineering, 63 (8-B, 3948).

Zemore, R. \& Shepel, L. (1989). Effects of breast cancer and mastectomy on emotional support and adjustment. Soc Sci Med, 28, 19-27.

Nina

Ogińska-Bulik 